\title{
HYPERTROPHIC OBSTRUCTIVE CARDIOMYOPATHY
}

\author{
BY

\section{J. COHEN*, H. EFFAT $\dagger$, J. F. GOODWIN, C. M. OAKLEY, AND R. E. STEINER} \\ From the Departments of Medicine and Radiodiagnosis, Postgraduate Medical School and Hammersmith Hospital, London \\ Received August 1, 1963
}

The term obstructive cardiomyopathy has been used to describe a rare disorder of heart muscle in which abnormal ventricular function is associated with massive cardiac hypertrophy (Goodwin et al., 1960). Since recent experience has shown that obstruction may be absent although massive ventricular hypertrophy always occurs, we have added the term "hypertrophic" to our definition. But the disorder most commonly produces obstruction to left ventricular outflow and simulates aortic stenosis. Many patients have also obstruction to right ventricular outflow, and others have obstruction to either left or right ventricular inflow. In some cases, the ventricular septum seems to be hypertrophied out of proportion to the remainder of the ventricular musculature, resulting in further accentuation of outflow tract obstruction.

Since Brock's first report of the hæmodynamic and pathological findings in "functional obstruction of the left ventricle" (Brock, 1957, 1959), and Teare's description of the pathology and clinical findings in "asymmetrical hypertrophy of the heart" (Teare, 1958), a host of publications has appeared describing this disorder, and an almost equally large number of terms has been used to describe these cases (Bercu et al., 1958; Bevegård, Jonsson, and Karlöf, 1962; Boiteau and Allenstein, 1961; Brachfeld and Gorlin, 1959, 1961 ; Braunwald et al., 1960; Brent et al., 1960; Goodwin et al., 1960; 1961; Hollman et al., 1960; Menges, Brandenburg, and Brown, 1961; Moberg, Fix, and Söderberg, 1962; Morrow and Braunwald, 1959; Nordenström and Ovenfors, 1962; Paré et al., 1961; Shabetai and McGuire, 1963; Soulié, Joly, and Carlotti, 1962; Wigle, Heimbecker, and Gunton, 1962).

The present communication amplifies our previous experience (Goodwin et al., 1962) and reports the findings in 29 patients who have been found to satisfy the clinical, hæmodynamic, and angiocardiographic criteria for diagnosis. The clinical and pathological features are reviewed briefly, and particular emphasis is given to hæmodynamic and radiological findings.

\section{Clinical Features}

The clinical features of the disorder are well recognized. Although the ætiology is unknown, a significant family incidence was present in 6 patients in this series, suggesting a genetic fault. In 2 of these patients, the presence of the disease in another member of the family has been documented at necropsy, and in one other by clinical examination of relations. In 3 other patients, presence of the disease in the family has been inferred from a history of sudden death in young blood relatives of the propositus. In another 5 patients, the history was somewhat suggestive that a second member of the family had been affected.

\footnotetext{
* Work done during the tenure of an Advanced Research Fellowship of the American Heart Association.
} $\uparrow$ On study leave from the Department of Radiology, University of Alexandria, U.A.R. 


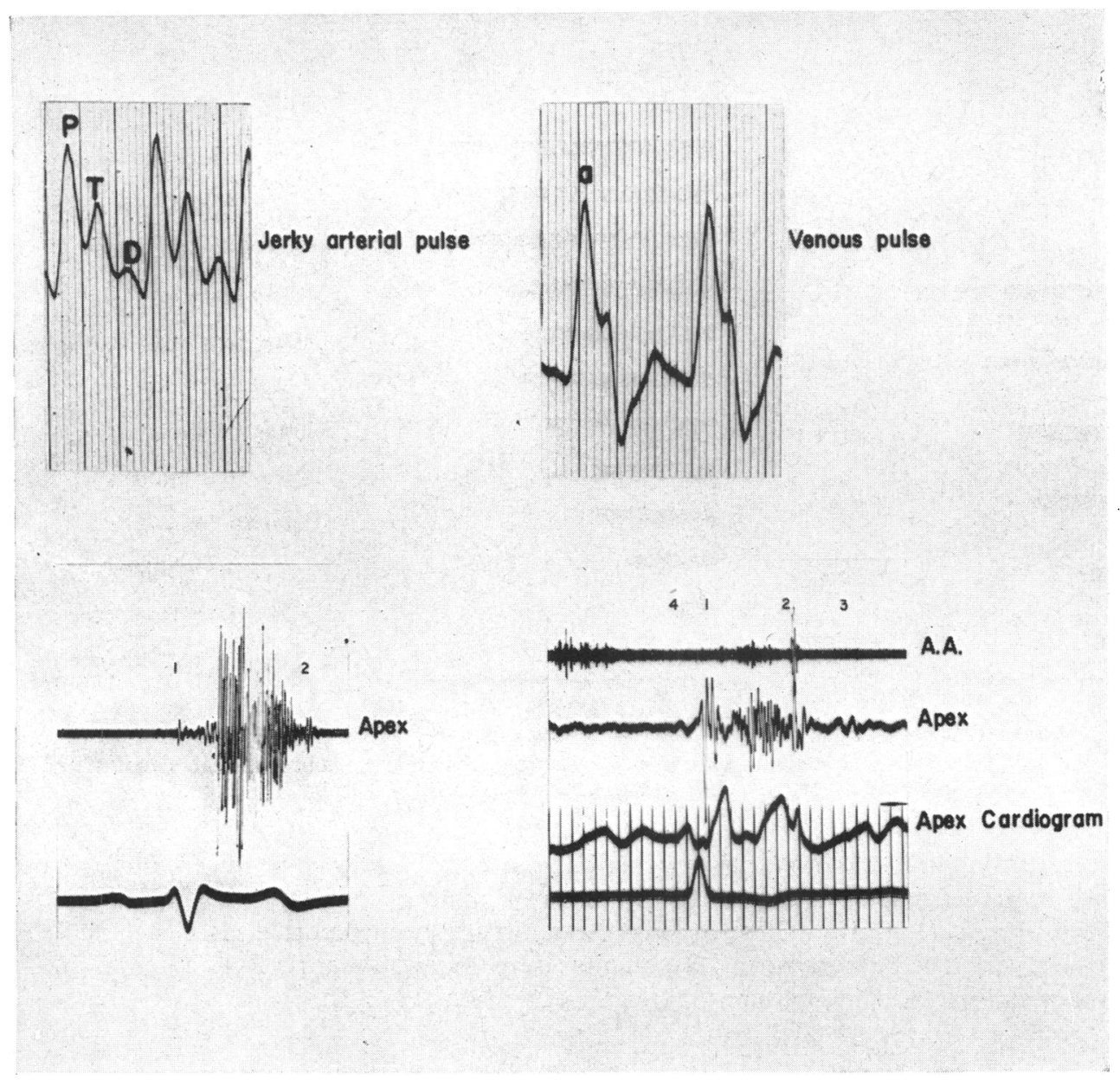

FIG. 1.-Notable physical signs include: fast-rising arterial pulse; ejection murmur of late onset; third and fourth heart sounds at the cardiac apex; and the "bifid" systolic apical impulse shown in the apex cardiogram. See text for details. $P=$ percussion wave. $T=$ tidal wave. $\mathrm{D}=$ dicrotic wave.

Symptoms include effort dyspnœa, angina pectoris, and syncope. There is a tendency to sudden death, and two patients in this series have died suddenly at home. One other patient died while awaiting investigation, but is not included in this report, though necropsy confirmed the clinical diagnosis. Three blood relatives of patients in this series have died suddenly and at necropsy have been found to have had obstructive cardiomyopathy. Notable physical signs (Fig. 1) include the following: the arterial pulse is fast rising (Boiteau and Allenstein, 1961; Brachfeld and Gorlin, 1959; Goodwin et al., 1960; Hancock, 1959; Morrow and Braunwald, 1959; Wigle, 1963); abnormal "flicking" "a" waves may be seen in the jugular venous pulse; the cardiac impulse is usually of left ventricular type and a "double" apical thrust can often be appreciated (Benchimol, Legler, and Dimond, 1963; Boiteau and Allenstein, 1961; Paré et al., 1961; Wigle et al., 1962). A systolic ejection murmur, often late in onset, is usually best heard at the left sternal edge; reversed splitting of the second heart sound may be found; third and fourth heart sounds are commonly heard; and a mid-diastolic murmur is sometimes present at the cardiac apex. Systolic ejection clicks and early diastolic murmurs are not heard and their absence helps to distinguish this condition from congenital valvar and discrete sub-valvar aortic stenosis (Fig. 2). 

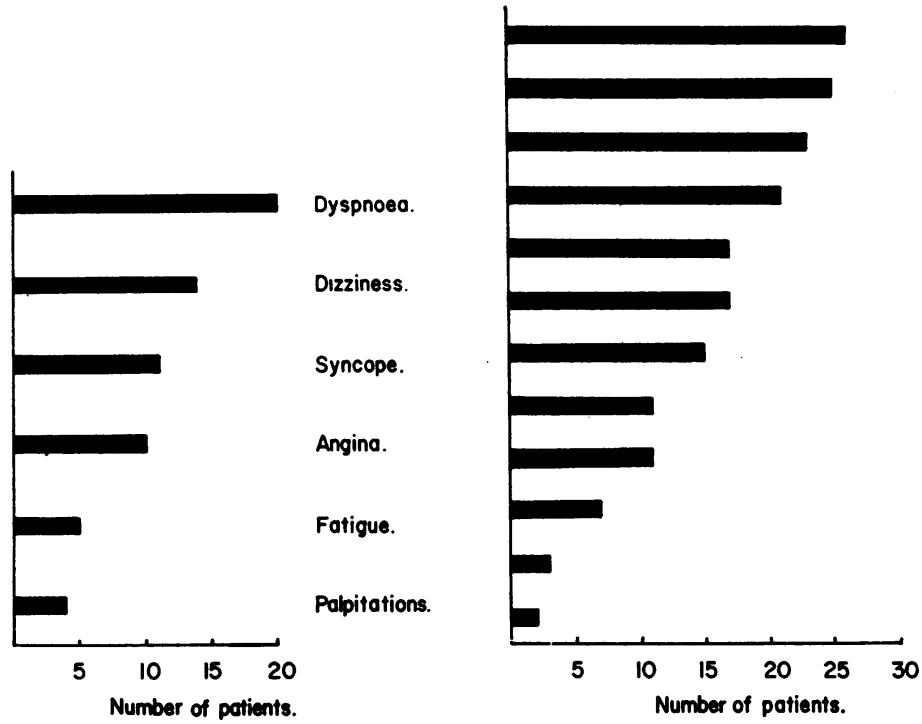

Fast rising arterial pulse.
Late onset ejection murmur, L.SE.
Left ventricular hypertrophy.
Third heart sound.
Abnormal 'o' wave in jugular venous pulse.
Fourth heart sound.
Mitrol diastolic murmur.
'Double' apex impulse.
Systolic thrill, L.S.E.
Right ventricular thrust.
Reversed splitting of second sound.
Tricuspid diastolic murmur.

Fig. 2.-Histograms showing the frequency of common symptoms and physical signs in the 29 patients reported. Only one patient was completely free from symptoms.

Electrocardiographic findings are extremely variable, but evidence of hypertrophy of both atria and both ventricles may be present. In certain cases, findings suggestive of ischæmic heart disease have been present (Fig. 3). These findings have already been reported (Hollister and Goodwin, 1963). The electrocardiograms of 3 patients have shown a short $P-R$ interval and a $Q R S$ appearance suggestive of premature ventricular excitation (Fig 3d).

\section{RADIOLOGY OF THE HEART}

The Plain Chest Film. The heart was of normal size in 15, and enlarged in 15 patients. The cardiac silhouette was not characteristic or constant in shape nor was there any clear pattern of chamber enlargement. In 13 patients, the shape of the heart was normal and in 9 it was globular. Right atrial enlargement was common; in 3 instances there was distinct left atrial enlargement alone, and in 4 distinct left ventricular enlargement alone (Fig. 4). The ascending aorta was normal in shape and not dilated in any patient. In 1 patient the pulmonary trunk was prominent and the smaller branches were small, the appearances suggesting pulmonary valve stenosis.

The pulmonary vascular pattern was normal in all but 3 patients, and in these the appearance of the pulmonary vessels suggested pulmonary hypertension. Vascular changes were present together with left atrial enlargement in 1 patient, suggesting a possible diagnosis of mitral stenosis (Fig. 5).

Aortic valve calcification has not been found in any patient in the series.

\section{Pathological Findings}

As has been reported previously, gross cardiac hypertrophy has been seen to involve the free walls of both ventricles as well as the ventricular septum which may be particularly massive. Atrial hypertrophy is usually present. Histologically, there is evidence of muscle fibre hypertrophy, and, in certain cases, the muscle bundles appear unusually large and their arrangement disordered; an 
I. II. III. OVL OVF VAR VI V3 VS V6

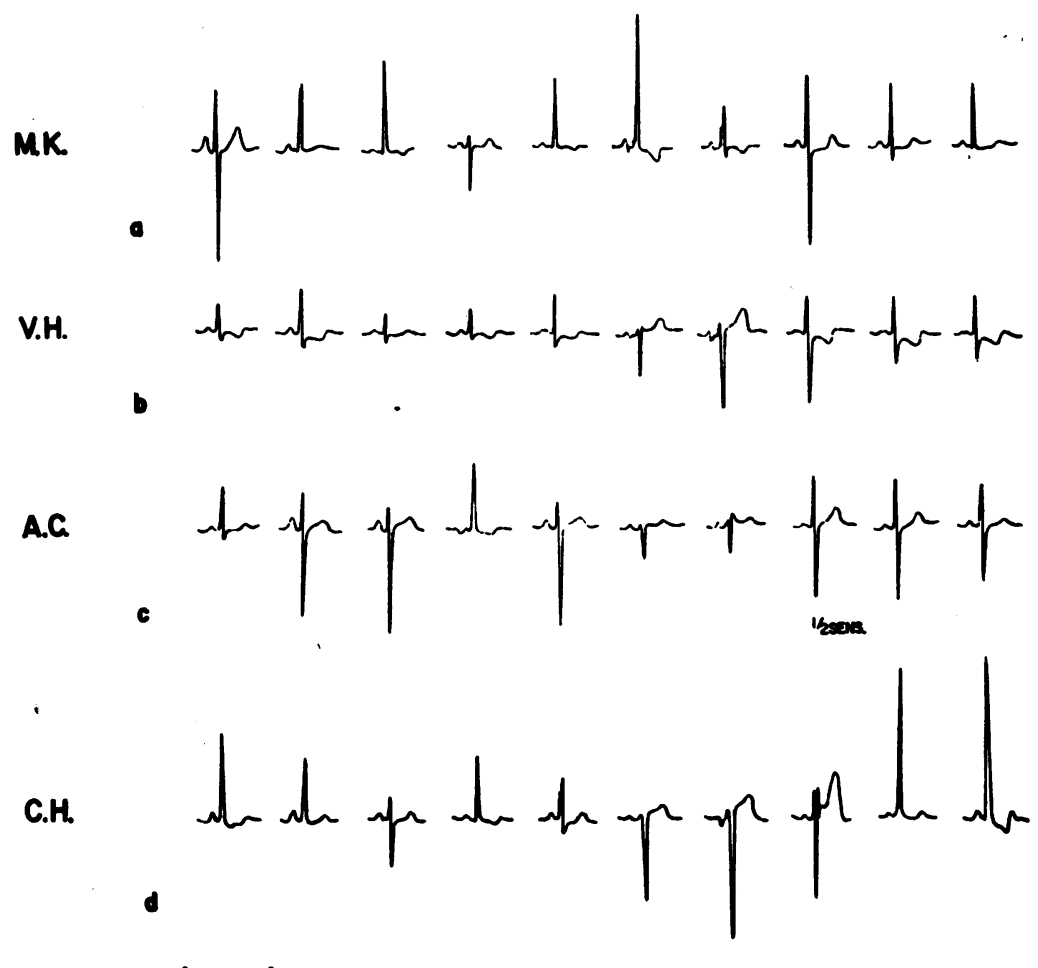

Ime. I

FIG. 3.-Electrocardiograms of four patients (Cases 1, 24, 13, and 19). (a) The deep $S$ in V3 suggests left ventricular hypertrophy, while the tall $R$ in V4R indicates right ventricular hypertrophy. The $\mathbf{P}$ waves indicate hypertrophy of both atria. (b) The ST segment depression and inverted T waves suggest myocardial ischæmia or left ventricular hypertrophy (digitalis had not been given). (c) Biventricular hypertrophy is suggested by the left axis and the deep $S$ in V5. There is enlargement of both atria. (d) Solitary left ventricular hypertrophy is present, and the short $\mathbf{P}-\mathbf{R}$ interval suggests ventricular pre-excitation.

excess of fibrous tissue may be present (Goodwin et al., 1960; Nordenström and Ovenfors, 1962; Paré et al., 1961; Soulié et al., 1962; Teare, 1958). In other specimens the hypertrophy is microscopically indistinguishable from that due to more common cardiac lesions such as hypertension or aortic valve stenosis. Furthermore, there is no obvious difference in the microscopic appearance of specimens obtained from the region of the outflow tract, compared with those obtained from other parts of the ventricles.

\section{HAMODYNAMIC OBSERVATIONS}

Twenty-five patients have undergone retrograde left heart catheterization, and the results of these investigations are presented in Table I. Considerable variations have been observed in left ventricular systolic pressure and in the systolic pressure gradient between left ventricle and aorta or peripheral artery. The systolic gradient was $50 \mathrm{~mm}$. or more in 15 of the 25 patients and was between 80 and $120 \mathrm{~mm}$. in 7 of them. The aortic pressure was as high as $160 \mathrm{~mm}$. in 4 but was below 120 in 10 of them. There was also considerable variability in arterial pulse form which was. full volume and fast rising when left ventricular outflow obstruction was present, but normal or small. 


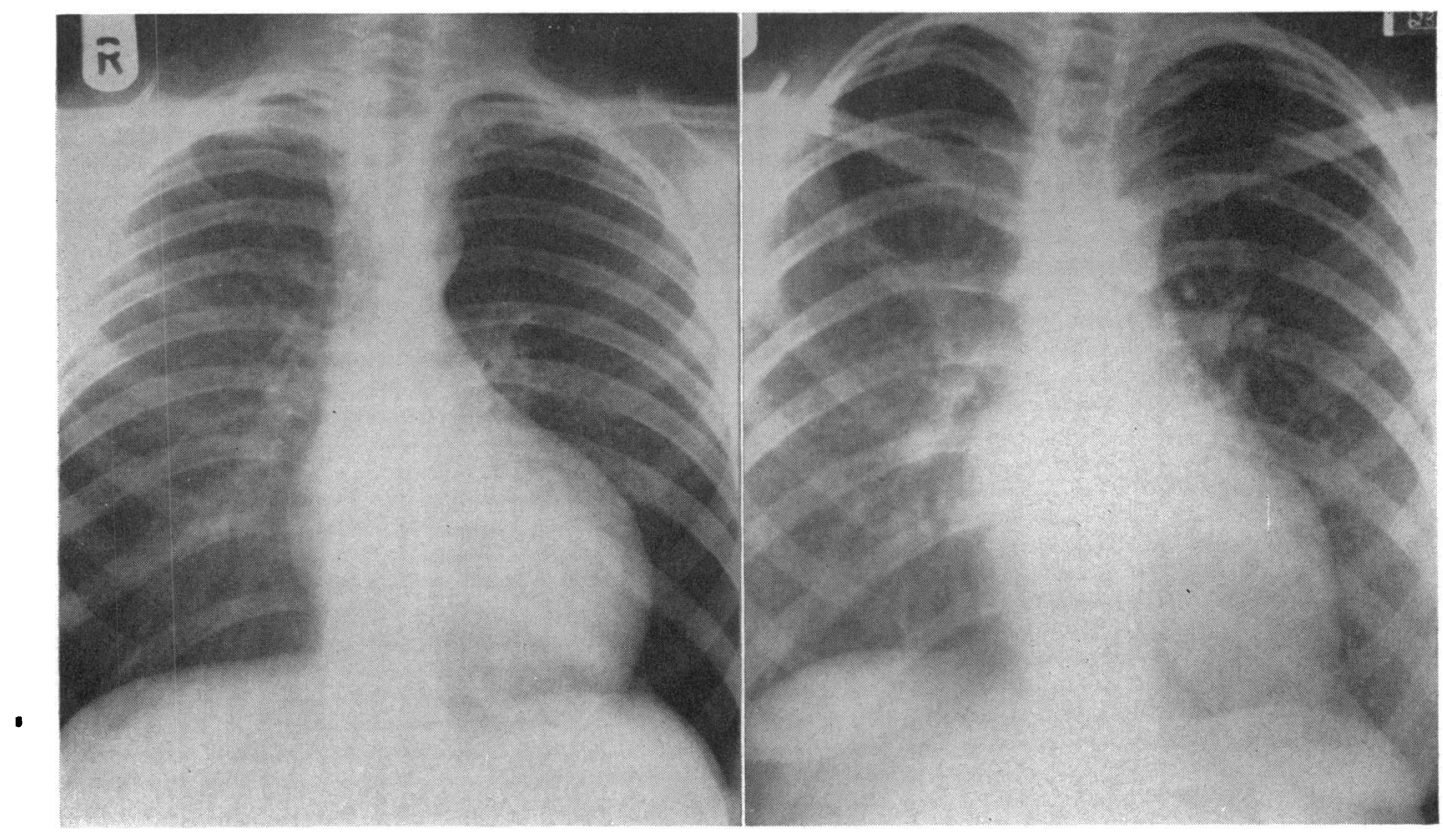

Fig. 4.-Postero-anterior 6-foot chest radiograph of Case 27 showing left ventricular enlargement, without obvious evidence of involvement of other chambers. There is no enlargement of the ascending aorta.

FIG. 5.-Postero-anterior 6-foot chest radiograph of Case 23 with enlargement of left atrium suggestive of mitral heart disease. The pulmonary vascular pattern indicates slight pulmonary hypertension.

volume in its absence. The most striking finding was the unusually high left ventricular enddiastolic pressure recorded in the majority of patients; in 17 it exceeded $20 \mathrm{~mm}$. $\mathrm{Hg}$. The level of the end-diastolic pressure bore no constant relation to either the left ventricular systolic pressure or to the systolic pressure gradient between left ventricle and aorta or peripheral artery.

Fig. 6 shows a withdrawal tracing from left ventricle to aorta in Case 16, and demonstrates that the systolic gradient, when present, was at subvalvar level. It is particularly noteworthy that 3 of the 4 patients who had no resting systolic gradient, but nevertheless satisfied the angiographic criteria for diagnosis of obstructive cardiomyopathy, had end-diastolic pressures in excess of $20 \mathrm{~mm}$. Hg (Fig. 7).

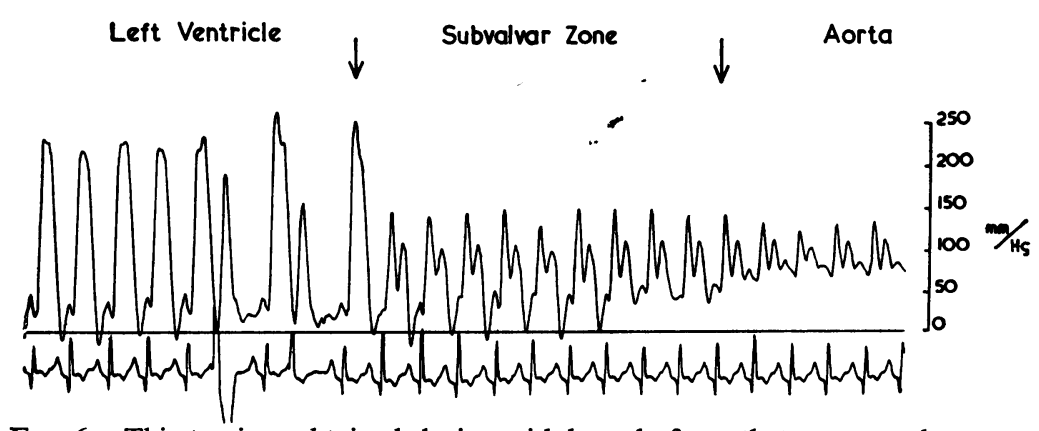

FIG. 6.-This tracing, obtained during withdrawal of a catheter across the outflow tract of the left ventricle in Case 16, demonstrates obstruction at subvalvar level. The left atrial " $a$ " wave is well shown in the ventricular pulse pattern. 


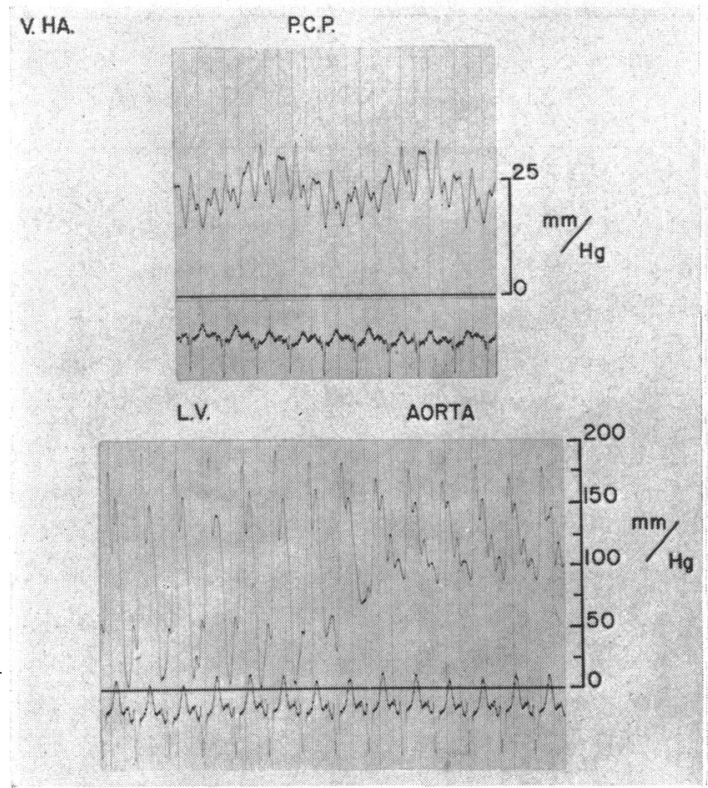

FIG. 7.-Withdrawal tracing obtained during left heart catheterization of Case 24, in whom no significant outflow gradient was found. However, the left ventricular end-diastolic pressure was much raised, as was the indirect left atrial pressure, measured on another occasion. $\mathrm{PCP}=$ pulmonary capillary pressure.

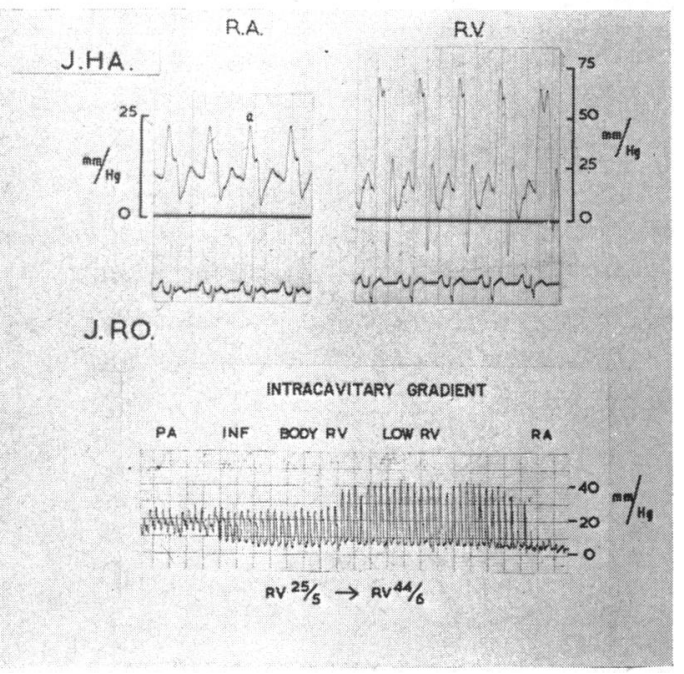

FIG. 8.-Findings obtained during right heart catheterization in 2 patients. Top left: right atrial pressure pulse in Case 4, showing prominent " $a$ " wave which, in top right, is shown to be well transmitted to the right ventricular pulse. The lower half of the figure demonstrates that gradients present within the right ventricle are found between the body and apex (low RV) of the right ventricle and the outflow tract.

As shown in Fig. 6 the "a" wave from the left atrial pulse is well transmitted to the ventricular pulse pattern. In addition, ventricular alternans has been found in three patients in this series.

Catheterization of the right side of the heart has been carried out in 24 patients. Evidence of obstruction to outflow from the right ventricle, defined as a gradient of more than $10 \mathrm{~mm}$. $\mathrm{Hg}$ has been found in 13 patients. The results of these studies are given in Table II. Systolic gradients when present were usually found between the body or apex of the right ventricle and the outflow tract (Fig. 8). Considerable variation was observed again in right ventricular systolic pressure; and variable systolic pressure gradients were found between right ventricle and pulmonary trunk. Although right ventricular end-diastolic pressures were sometimes modestly raised, the extreme elevations found during study of the left heart were not generally encountered. In 9 patients, strikingly elevated pulmonary capillary pressures were recorded (Fig. 7 and Table II). Mean right atrial pressures were not remarkable, but prominent " $a$ " waves from the right atrial pulse were well transmitted to the right ventricular pulse pattern (Fig. 8).

As reported previously (Goodwin et al., 1961), there is hæmodynamic evidence that the disorder is progressive in certain patients.

\section{ANGIOCARDIOGRAPHY}

Angiocardiography was performed in 28 patients. Retrograde left ventricular angiography was carried out in 25 and right ventricular angiography in 20 . Solitary left ventricular hypertrophy was demonstrated in 8 patients, solitary right ventricular hypertrophy in 3, and biventricular hypertrophy in 17. Mitral regurgitation was demonstrated in 10 of the 25 patients investigated by retrograde left ventricular angiography. 
TABLE I

Left Ventricular and Systemic Arterial Pressures in Hypertrophic Obstructive Cardiomyopathy

\begin{tabular}{|c|c|c|c|c|c|}
\hline \multirow{2}{*}{$\begin{array}{l}\text { Case No. and } \\
\text { initials }\end{array}$} & \multicolumn{2}{|c|}{ Left ventricle (mm. $\mathrm{Hg})$} & \multicolumn{2}{|c|}{ Aorta or peripheral artery $(\mathrm{mm} . \mathrm{Hg}$ ) } & \multirow{2}{*}{$\begin{array}{l}\text { Systolic } \\
\text { gradient }\end{array}$} \\
\hline & Systolic & Diastolic & Systolic & Diastolic & \\
\hline $\begin{aligned} 1 & \text { M.K. } \\
2 & \text { J.M. } \\
3 & \text { R.H. } \\
4 & \text { J.Ha. } \\
5 & \text { J.R. } \\
6 & \text { S.B. } \\
7 & \text { R.F. } \\
8 & \text { T.W. } \\
9 & \text { K.L. } \\
10 & \text { H.C. } \\
11 & \text { J.C. } \\
12 & \text { B.A. } \\
13 & \text { A.C. } \\
14 & \text { S.E. } \\
15 & \text { B.P. } \\
16 & \text { J.B. } \\
17 & \text { N.H. } \\
18 & \text { L.T. } \\
19 & \text { C.H. } \\
20 & \text { A.S. } \\
21 & \text { A.L. } \\
22 & \text { O.O. } \\
23 & \text { M.T. } \\
24 & \text { V.H. } \\
25 & \text { D.G. } \\
29 & \text { A.J. }\end{aligned}$ & $\begin{array}{l}163 \\
240 \\
170 \\
130 \\
165 \\
150 \\
120 \\
100 \\
195 \\
180 \\
187 \\
220 \\
168 \\
160 \\
160 \\
250 \\
137 \\
180 \\
200 \\
240 \\
145 \\
210 \\
100 \\
195 \\
150 \\
180\end{array}$ & $\begin{array}{r}20 \\
0 \\
23 \\
25 \\
55 \\
0 \\
10 \\
20 \\
40 \\
25 \\
12 \\
15 \\
28 \\
25 \\
20 \\
25 \\
10 \\
30 \\
0 \\
10 \\
25 \\
40 \\
25 \\
56 \\
0 \\
30\end{array}$ & $\begin{array}{r}112 \\
160 \\
110 \\
120 \\
100 \\
100 \\
120 \\
100 \\
115 \\
130 \\
155 \\
162 \\
126 \\
72 \\
85 \\
130 \\
87 \\
132 \\
110 \\
120 \\
132 \\
210 \\
100 \\
183 \\
145 \\
124\end{array}$ & $\begin{array}{r}55 \\
100 \\
65 \\
60 \\
65 \\
75 \\
60 \\
67 \\
60 \\
75 \\
95 \\
108 \\
74 \\
52 \\
40 \\
75 \\
53 \\
75 \\
72 \\
60 \\
80 \\
125 \\
50 \\
90 \\
85 \\
75\end{array}$ & $\begin{array}{r}51 \\
80 \\
60 \\
10 \\
65 \\
50 \\
0 \\
0 \\
80 \\
50 \\
32 \\
88 \\
42 \\
88 \\
75 \\
120 \\
50 \\
48 \\
90 \\
120 \\
13 \\
0 \\
0 \\
12 \\
5 \\
56\end{array}$ \\
\hline
\end{tabular}

TABLE II

Right Ventricular, Pulmonary Arterial, and Indirect left Atrial Pressures in Hypertrophic Obstructive CARDIOMYOPATHY

\begin{tabular}{|c|c|c|c|c|c|c|}
\hline \multirow{2}{*}{$\begin{array}{l}\text { Case No. and } \\
\text { initials }\end{array}$} & \multicolumn{2}{|c|}{ Right ventricle (mm. $\mathbf{H g})$} & \multicolumn{2}{|c|}{ Pulmonary artery (mm. Hg) } & \multirow{2}{*}{$\begin{array}{l}\text { Systolic } \\
\text { gradient }\end{array}$} & \multirow{2}{*}{$\begin{array}{c}\text { Mean indirect } \\
\text { left atrial } \\
\text { pressure (PCVP) }\end{array}$} \\
\hline & Systolic & Diastolic & Systolic & Diastolic & & \\
\hline $\begin{aligned} 1 & \text { M.K. } \\
2 & \text { J.M. } \\
3 & \text { R.H. } \\
4 & \text { J.Ha. } \\
5 & \text { J.R. } \\
6 & \text { S.B. } \\
7 & \text { R.F. } \\
8 & \text { T.W. } \\
9 & \text { K.L. } \\
10 & \text { H.C. } \\
11 & \text { J.C. } \\
13 & \text { A.C. } \\
14 & \text { S.E. } \\
15 & \text { B.P. } \\
16 & \text { J.B. } \\
19 & \text { C.H. } \\
21 & \text { A.L. } \\
22 & \text { O.O. } \\
23 & \text { M.T. } \\
24 & \text { V.H. } \\
25 & \text { D.G. } \\
26 & \text { M.F. } \\
27 & \text { R.D. } \\
28 & \text { J.He. }\end{aligned}$ & $\begin{array}{r}108 \\
45 \\
44 \\
70 \\
60 \\
80 \\
26 \\
37 \\
68 \\
57 \\
52 \\
50 \\
20 \\
30 \\
48 \\
28 \\
59 \\
63 \\
39 \\
35 \\
40 \\
60 \\
60 \\
16\end{array}$ & $\begin{array}{r}0 \\
0 \\
6 \\
10 \\
8 \\
10 \\
0 \\
6 \\
15 \\
12 \\
0 \\
5 \\
0 \\
8 \\
10 \\
0 \\
7 \\
7 \\
12 \\
3 \\
4 \\
3 \\
0 \\
2\end{array}$ & $\begin{array}{l}42 \\
30 \\
25 \\
40 \\
56 \\
29 \\
24 \\
30 \\
57 \\
32 \\
38 \\
26 \\
20 \\
27 \\
40 \\
28 \\
38 \\
35 \\
31 \\
35 \\
30 \\
24 \\
45 \\
15\end{array}$ & $\begin{array}{r}30 \\
5 \\
12 \\
23 \\
24 \\
11 \\
8 \\
9 \\
23 \\
19 \\
9 \\
16 \\
10 \\
10 \\
14 \\
10 \\
7 \\
11 \\
4 \\
20 \\
10 \\
13 \\
15 \\
8\end{array}$ & $\begin{array}{r}66 \\
15 \\
19 \\
30 \\
4 \\
51 \\
2 \\
7 \\
11 \\
25 \\
14 \\
24 \\
0 \\
3 \\
8 \\
0 \\
21 \\
28 \\
8 \\
0 \\
10 \\
36 \\
15 \\
1\end{array}$ & $\begin{array}{r}15 \\
2 \\
12 \\
21 \\
6 \\
6 \\
11 \\
30 \\
12 \\
14 \\
11 \\
15 \\
20 \\
20 \\
18 \\
11 \\
11 \\
23 \\
8 \\
20 \\
-\end{array}$ \\
\hline
\end{tabular}



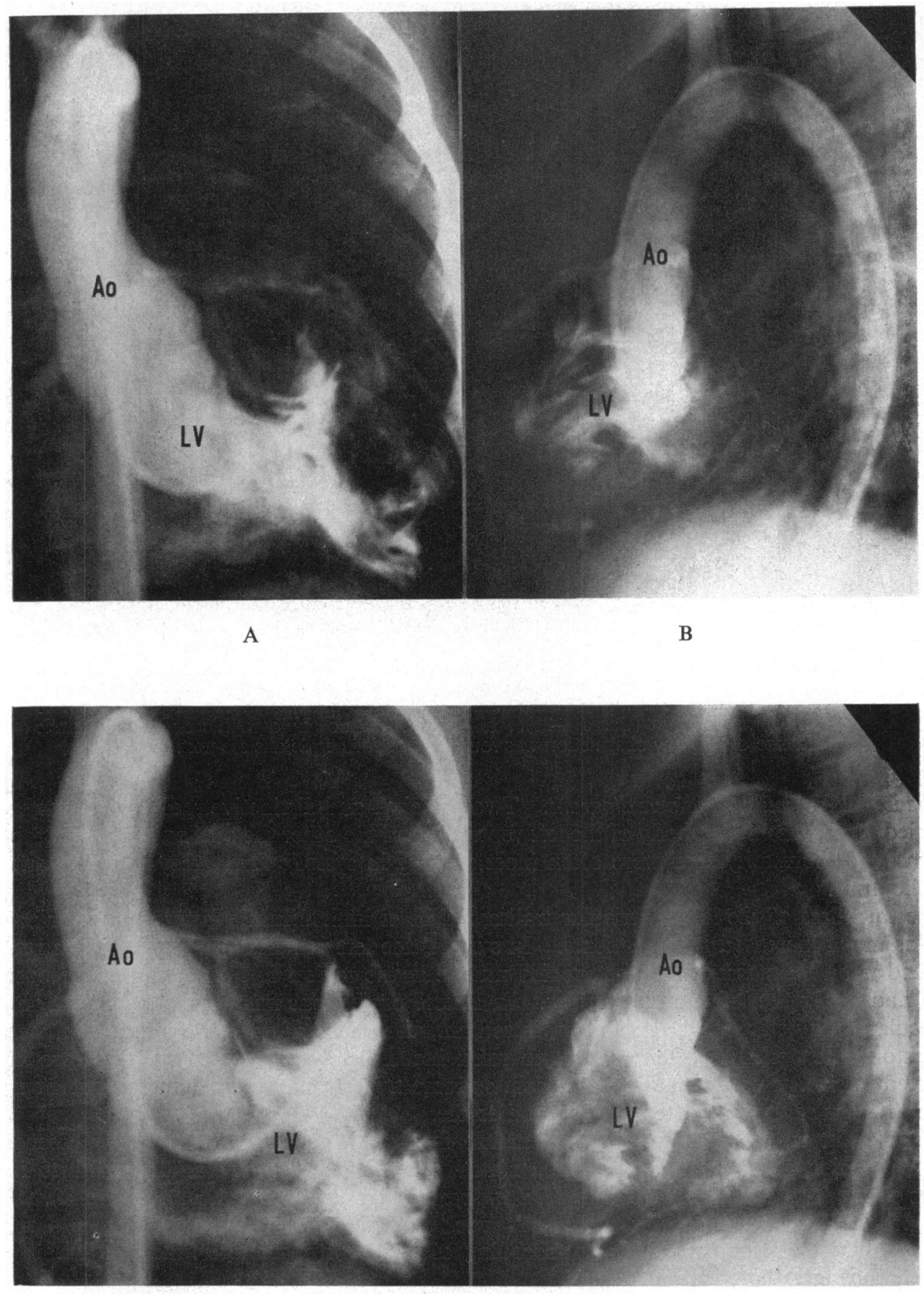

C

D

Fig. 9.- - Left ventricular angiogram (Case 4). (A) Systole=antero-posterior view. (B) Systole=lateral view. (C) Diastole = antero-posterior view. (D) Diastole=lateral view. The conical narrowing below the aortic valve in diastole can be seen in $\mathrm{D}$, while $\mathrm{A}, \mathrm{B}$, and $\mathrm{C}$ show the characteristic muscle masses encroaching on the ventricular cavity (see text). Ao=aorta. $L V=$ left ventricle. 

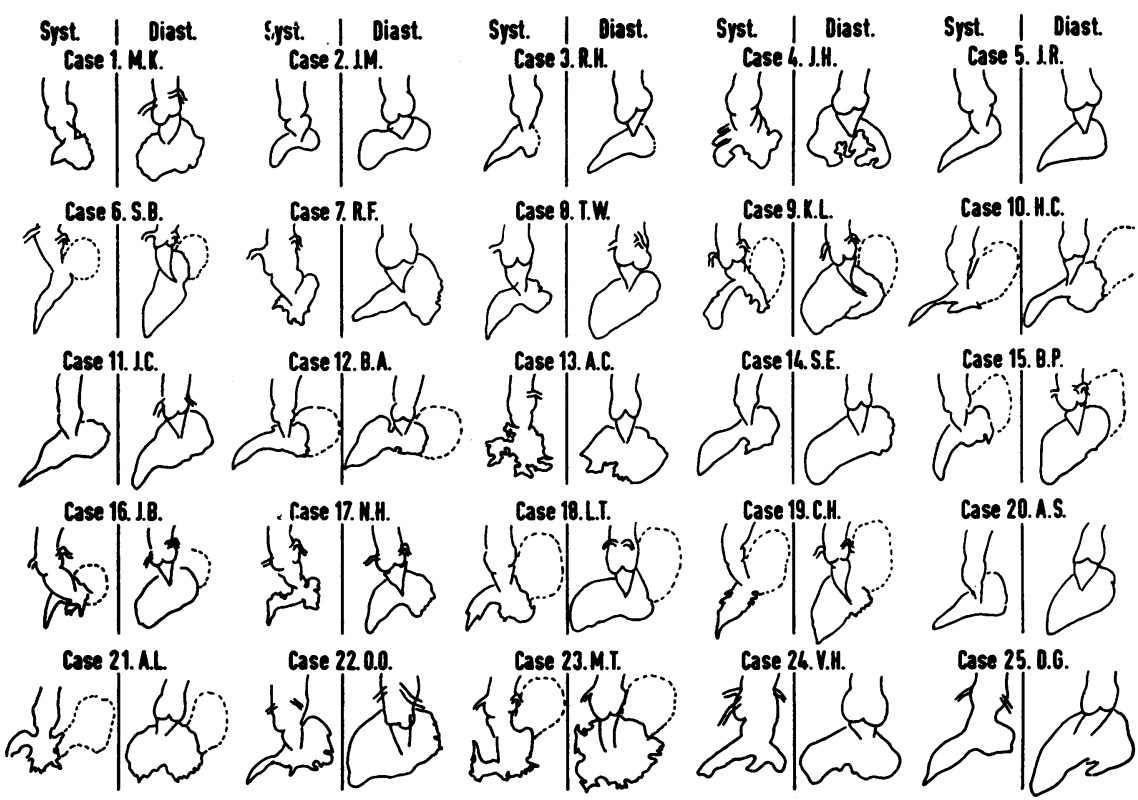

FIG. 10.-Outline tracings of selected films from the left ventricular angiograms of the 25 patients in whom this study was performed. Only the lateral view is shown: both systolic and diastolic phases are represented. The area within the solid lines defines the left ventricular cavity and proximal ascending aorta. The outline of the left atrium has been shown as a dotted line in those cases in which mitral regurgitation was present. There is striking similarity in the findings in those patients in whom obstruction to outflow was present (Cases 1-20). In Cases 21-25 no angiographic or hæmodynamic evidence of outflow obstruction was found. For further details see text.

The Left Ventricular. Angiocardiogram. Two principal and distinctive radiological patterns were identified, one affecting the body of the left ventricle, and the other the outflow tract. Although the patterns of abnormality seen were often most striking in systolic films, they were present also in diastolic films.

The thickness of the left ventricular wall could be estimated in the antero-posterior projection and was much increased in all patients. In systole, the left ventricular cavity appeared to be encroached upon by masses of hypertrophied muscle in the region of the septum at the base of the heart, and along the left cardiac border. In lateral projections muscle encroachment on the left ventricular cavity was well seen, and produced an appearance of eccentric muscular hypertrophy. In diastole, the ventricle often seemed to relax incompletely and its cavity therefore appeared restricted in size. In patients with the most extreme hypertrophy muscle encroachment upon the left ventricular cavity was detected even in diastole.

Translucent areas, apparent in the ventricle filled with contrast medium, were seen in both antero-posterior and lateral projections, in both systole and diastole, and seemed to represent masses of hypertrophied muscle bulging into the ventricular cavity (Fig. 9A, B, C, and D). Between these protruding muscle masses, numerous pockets of contrast medium could be seen. Such pockets could be responsible for the recording of misleading pressure gradients within the left ventricle during catheterization.

In 20 patients, the outflow tract of the left ventricle took the appearance of an inverted cone beneath the aortic valve. This appearance was seen in both systolic and diastolic films, but was more striking in the latter (Fig. 9A and 10). In systole the outflow tract of the left ventricle failed to open completely with production of a constriction between the body of the left ventricle and the subvalvar region of the outflow tract. This pattern correlated well with the hæmodynamic evidence 


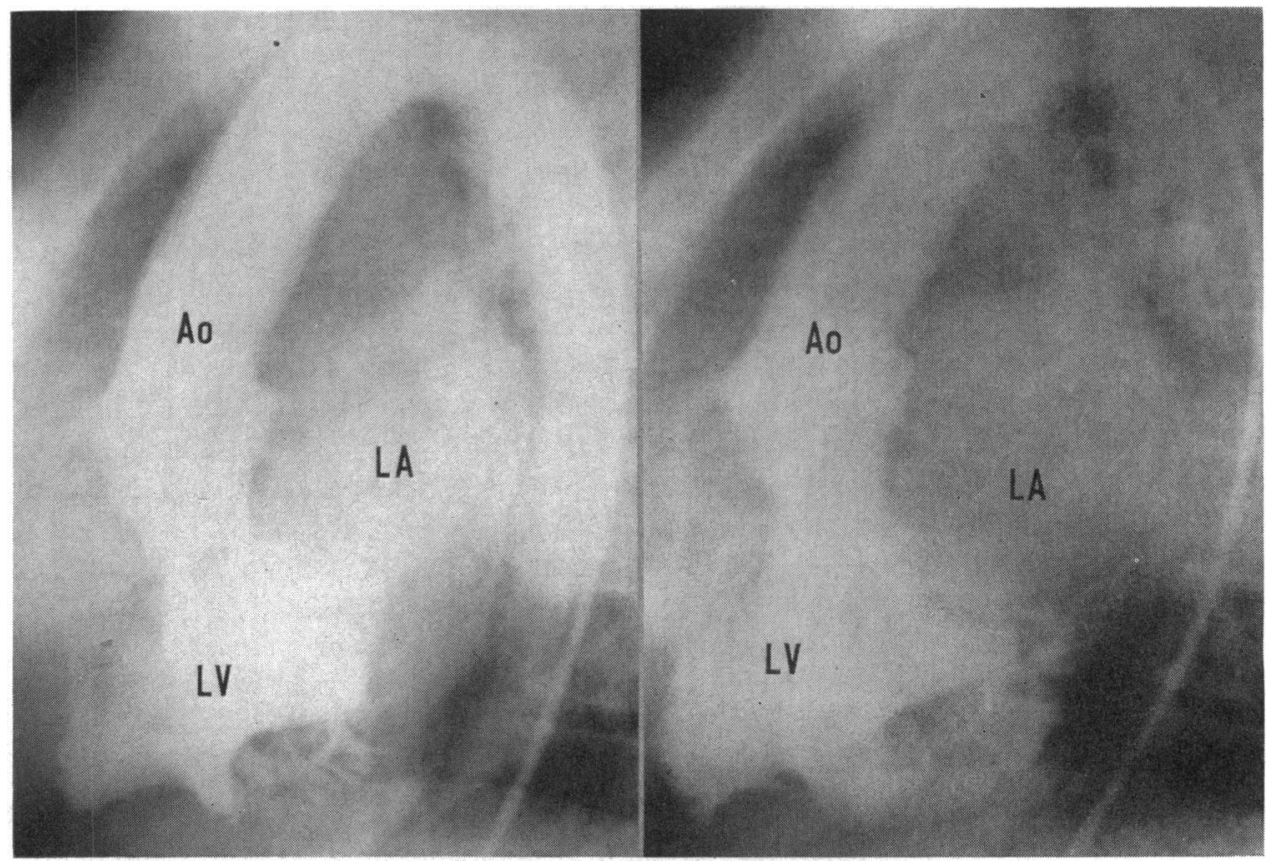

(A)

(B)

FIG. 11.-Lateral view of the left ventricular angiogram in Case 23; (A), systolic film; (B), diastolic film. No hæmodynamic or angiographic evidence of obstruction was found in this patient but massive irregular hypertrophy was seen. The left atrium is opacified, indicating mitral regurgitation (see text). Ao=aorta. LA=left atrium. $L V=$ left ventricle.

of outflow tract obstruction in all but 2 patients (Cases 7 and 8 ). In these it is possible that the catheter failed to pass the outflow tract obstruction, with the result that although the angiographic appearances were those of severe outflow tract obstruction, systolic gradients between left ventricle and peripheral artery were not found during retrograde catheterization. In the 5 in whom there was no significant angiographic evidence of outflow tract obstruction, there was no significant gradient found between left ventricle and aorta (Fig. 11A and B).

The coronary arteries filled well in all patients, and in many were unusually large. The left atrium became opacified in 10 patients, indicating mitral regurgitation, which varied in degree from slight to severe (Steiner and Hollman, 1962) (Fig. 11). The aortic valve was tricuspid, free of calcium, and freely mobile in all patients. No dilatation of the ascending aorta was noted.

Left ventricular cine-angiography was carried out in 4 patients. Failure of the outflow tract to open in systole was demonstrated in all 4, and the subvalvar cone was again noted to be most striking in diastole. Mitral regurgitation was found in 3 of the 4 patients and appeared to occur late in systole.

The Right Ventricular Angiocardiogram. The principal abnormal finding in the right ventricular angiogram, seen both in systole and in diastole, was distortion of the right ventricular cavity by the hypertrophied ventricular septum which encroached upon it (Fig. 12). Although the outline of the right ventricle was smooth in some cases, in others it was extremely irregular, with masses and ridges of muscle bulging into the cavity. Pockets of contrast medium, between these muscular ridges, similar to those seen in left ventricular angiograms, were again noted. Hypertrophy was not confined to the ventricular septum, but was also evident at the base of the right ventricle. Filling defects in the contrast-filled ventricle were thought to represent hypertrophied muscle as on the left side. 

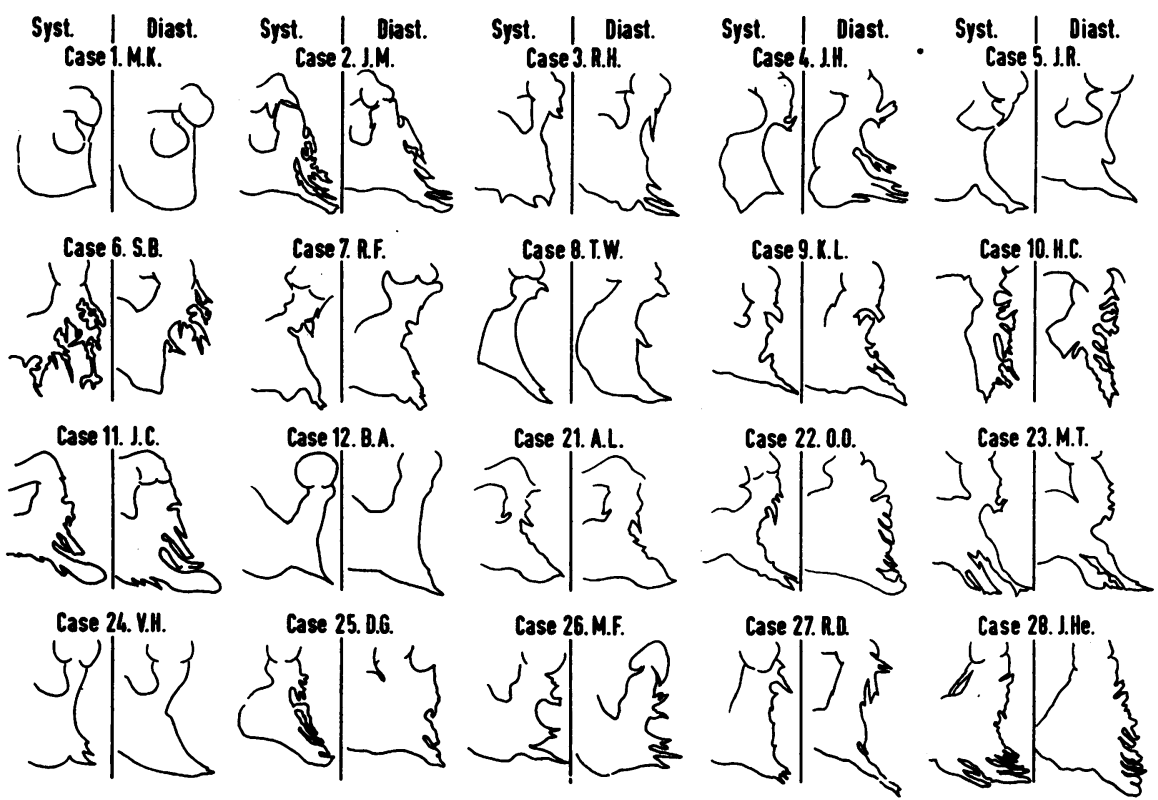

Fig. 12.-Outline tracings of selected films from the right ventricular angiogram of the 20 patients in whom this study was performed. Only the antero-posterior view is shown: both systolic and diastolic findings are represented. The area within the solid lines defines the right ventricular cavity and pulmonary trunk (see text).

A systolic constriction of varying severity was found at the junction of the outflow tract and body of the right ventricle in all patients. In diastolic films, this constriction was seen to relax only partially. It was lower in the body of the ventricle than usually occurs in patients with congenital infundibular pulmonary stenosis (Fig. 13A, B, C, and D).

In no patient was there any abnormality of the tricuspid or pulmonary valve.

\section{TREATMENT}

Ten patients in this series with an appropriate left ventricular-aortic gradient and significant symptoms of angina and syncope have been operated upon by Mr. W. P. Cleland or Mr. H. H. Bentall. Variable and small amounts of tissue have been resected from the outflow tract of the left ventricle, a ventriculomyotomy performed, and, in 9 patients, left bundle-branch block was produced. Variable gradients between left ventricle and aorta were found at operation, and in some cases, although a gradient had been present during catheterization, no gradient was found at thoracotomy, confirming the experience of others (Braunwald et al., 1960; Nordenström and Ovenfors, 1962). Two patients died as a result of operation, 2 are symptomatically improved but have a high venous pressure, and 6 have had significant improvement in symptoms and relief of the signs of outflow obstruction. In view of the small amounts of tissue removed at operation, the deep incision in the hypertrophied muscle and perhaps the production of left bundle-branch block may be crucial in achieving a successful result (Wigle, Chrysohou, and Bigelow, 1963), possibly by delaying the onset of and termination of systolic ejection and by diminishing the force of contraction of the left ventricle (Bourassa, Boiteau, and Allenstein, 1962).

As part of the study of ventricular function in this disorder, investigations have been initiated to examine the influence of drugs on outflow tract obstruction in these patients. The findings of others (Braunwald and Ebert, 1962; Shabetai and McGuire, 1963; Whalen et al., 1963), that inotropic agents may increase outflow tract obstruction have been confirmed. The observation (Braunwald 


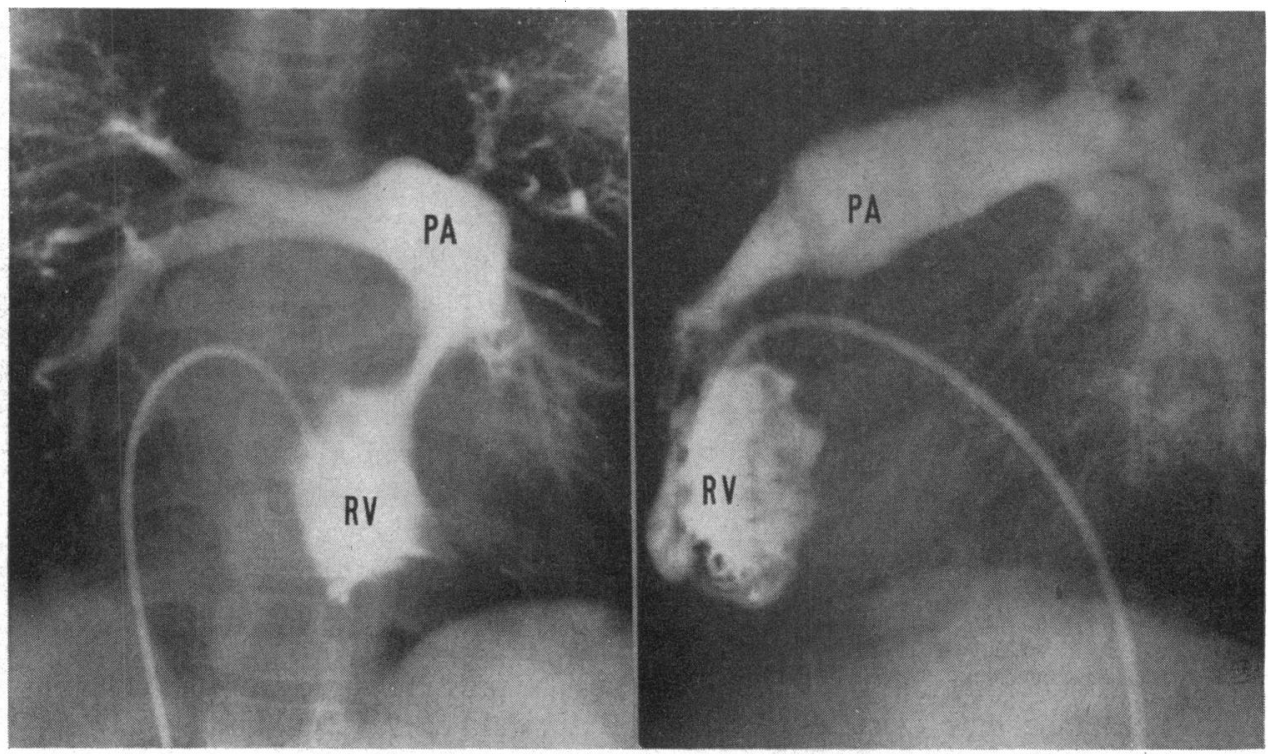

(A)

(B)

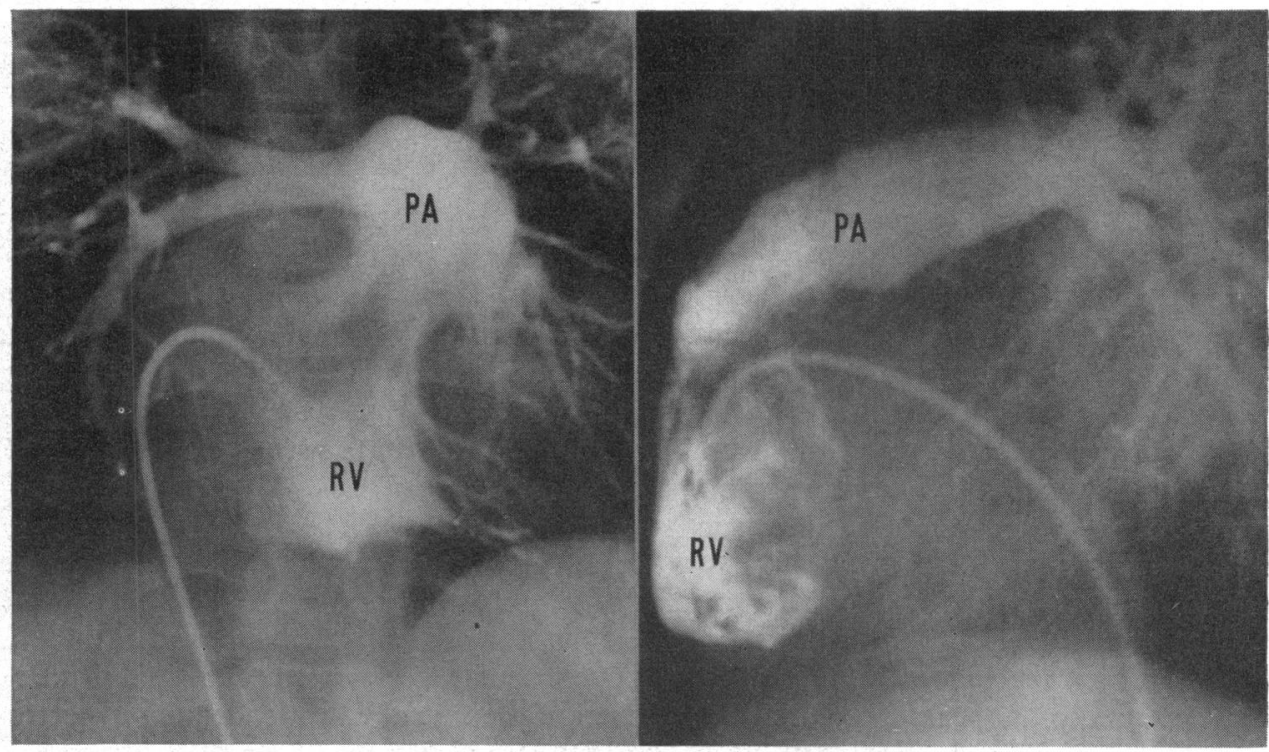

(C)

(D)

FIG. 13.-Right ventricular angiogram in Case 4. (A) Systole =antero-posterior view. (B) Systole= lateral view. (C) Diastole=antero-posterior view. (D) Diastole=lateral view. Encroachment by the ventricular septum on the outflow tract of the right ventricle is especially well seen in the antero-posterior view (see text). PA=pulmonary artery. $R V=$ right ventricle.

and Ebert, 1962) that agents that selectively raise peripheral blood pressure, while having no direct cardiac action, may reduce outflow obstruction has also been confirmed using phenylephrine. In addition, preliminary results obtained using "nethalide" (Black and Stephenson, 1962), an experimental beta-adrenergic blocking agent, suggest that this drug is able to reduce obstruction in certain 
cases, when used acutely during left heart catheterization. However, whether this drug will have any use as a therapeutic agent remains to be determined. The possibility is at present under study.

\section{Discussion}

The clinical, pathological, and radiographic findings in the 29 patients reported in this paper are in agreement with the reported findings of others. The central feature of this disorder is massive generalized cardiac hypertrophy associated with abnormal ventricular function.

Symptoms and signs are consequences of impaired ventricular filling, abnormal ventricular ejection, mitral regurgitation, and the occasional arrhythmias that may be associated with this disorder. Congestive cardiac failure is unusual and has occurred in only one patient in this series.

Impaired ventricular filling in certain cases is a function of mechanical obstruction to ventricular inflow by massive septal hypertrophy. However, inadequate diastolic function of ventricular muscle probably results in functional inflow obstruction in an even larger number of cases. The extreme rises in left ventricular end-diastolic pressure observed in these cases and the faithful transmission of atrial contraction waves to the ventricular pressure curve are hæmodynamic manifestations of this inadequate diastolic function. Braunwald et al. (1960) and Wigle et al. (1962) have ascribed this to inelasticity or lack of compliance of the massively hypertrophied muscle, and this seems a reasonable suggestion. In certain cases, however, the level of end-diastolic pressure seems out of proportion to the degree of hypertrophy assessed angiographically. It, therefore, remains to be determined whether these rises in end-diastolic pressure are simply the result of gross hypertrophy or whether there is a fault in muscular behaviour unique to this disorder to account for this finding.

Impaired ventricular emptying appears to be due both to mechanical obstruction by hypertrophied muscle encroaching upon the ventricular outflow tracts and to failure of the outflow tract, at least in the left ventricular ejection, as demonstrated cine-angiographically. A noteworthy finding is the variability of obstruction to outflow in these patients. The clinical signs of obstruction to outflow have been found to vary in certain cases from day to day. Ejection murmurs vary in length and intensity, and the pulse may be fast rising one day when the murmur is loud and obstruction maximal, and normal another. In spite of this variability in the pulse our experience has otherwise confirmed that of Wigle (1963) who found the fast-rising pulse of value in distinguishing patients with obstructive cardiomyopathy from those with discrete outflow tract obstruction. In our experience no patient with discrete subvalvar or valvar aortic stenosis has shown the fast-rising pulse almost invariably seen in patients with obstructive cardiomyopathy. The systolic pressure gradient across the left ventricular outflow tract may vary considerably when measured at different times, for example before and after angiography or inotropic drugs, and before and at thoracotomy. It should be noted that the cardiac output in these patients is high or normal. It is apparent, therefore, in view of the high ventricular pressures recorded, that ventricular work is either normal or increased.

Mitral regurgitation appears to be due to distortion of the mitral valve leaflets by hypertrophied muscle and, in certain cases, to displacement of the attachments of the mitral valve by hypertrophied muscle. In one patient at operation, displacement of the attachments of the anterior leaflet of the mitral valve into the outflow of the left ventricle was seen, and the appearances were similar to those described by Björk, Hultquist, and Lodin (1961). It is our impression that this displacement of the mitral valve attachments follows upon severe hypertrophy in this disorder, rather than that an anomaly of insertion of the mitral valve attachments leads to outflow obstruction and hypertrophy.

From the point of view of diagnosis, our experience indicates that when the clinical findings are considered as a group, a diagnosis can be made at the bedside with confidence. The electrocardiogram offers further assistance, as does the plain film of the chest, which by the absence of aortic valve calcification and of post-stenotic dilatation of the ascending aorta, helps to distinguish obstructive 


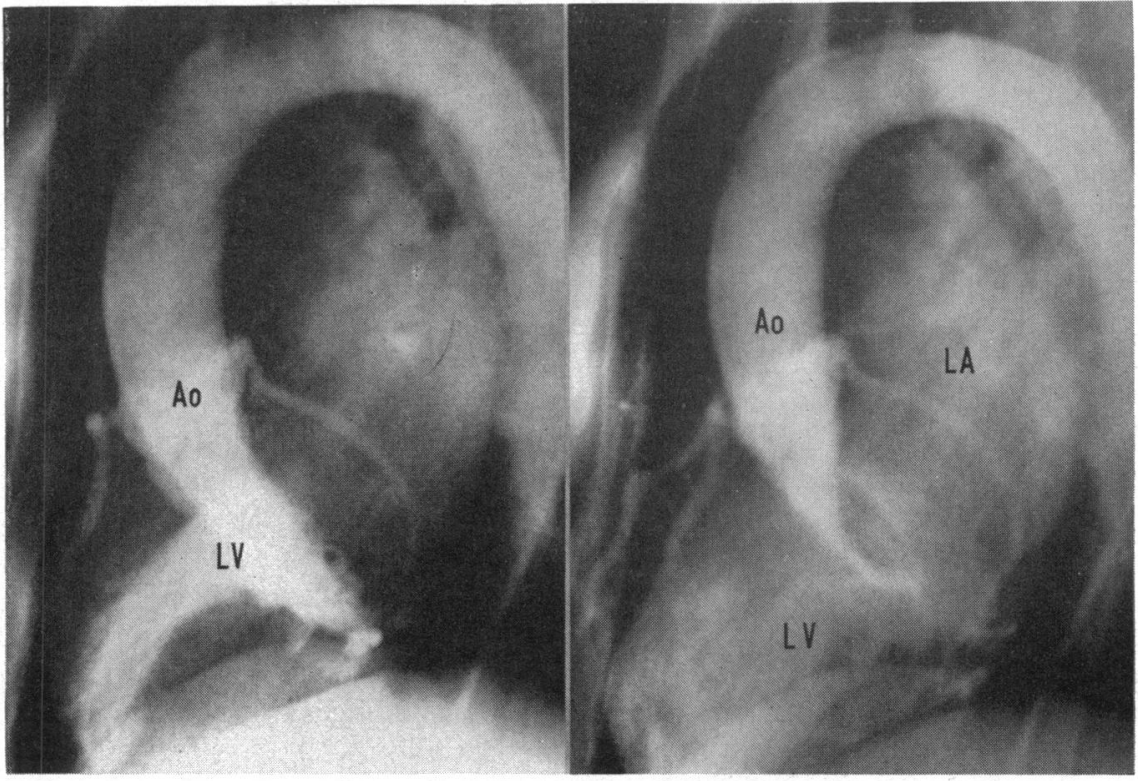

(A)

(B)
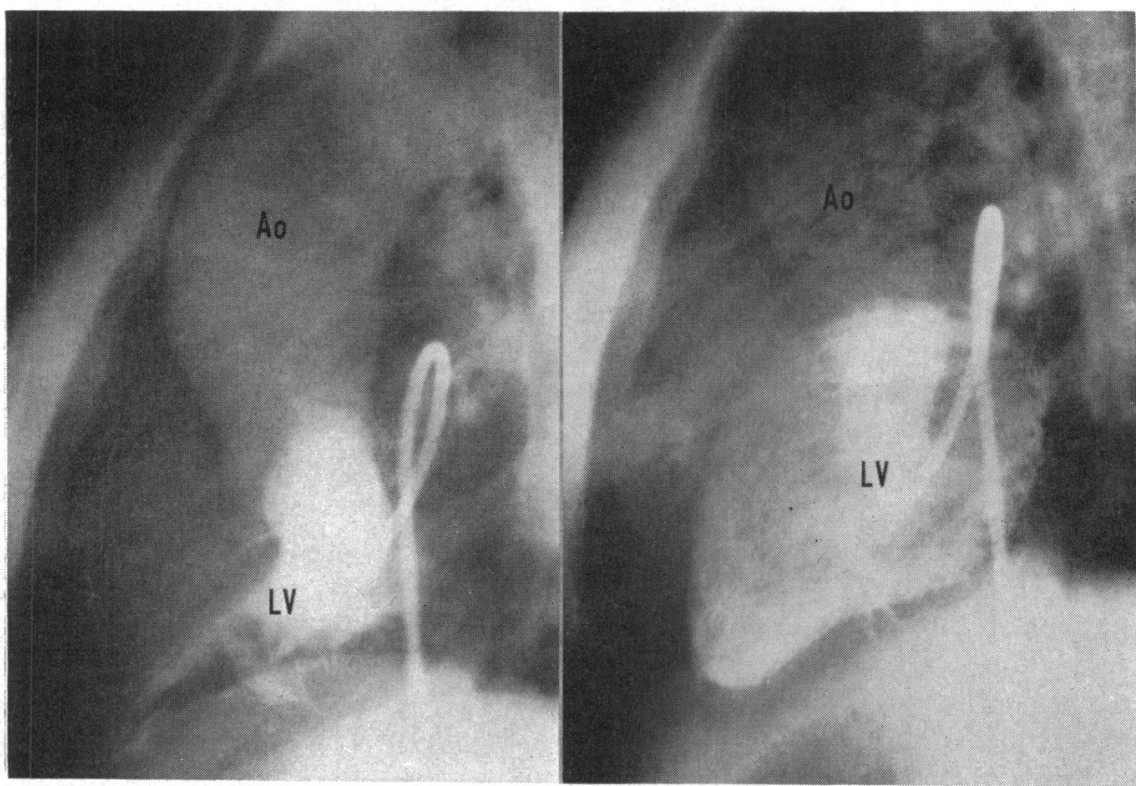

(C)

(D)

FIG. 14.-A comparison of the angiographic appearances of obstructive cardiomyopathy and aortic valve stenosis. The lateral view is shown in all films. (A) and (B) are films of Case 9 with hypertrophic obstructive cardiomyopathy: (C) and (D) are those of a 12-year-old girl with severe aortic valve stenosis, proven at operation. (A) and (C) are systolic films: (B) and (D) are diastolic films. Whereas the outflow tract in the patient with aortic valve stenosis is widely open in early systole and in diastole, it is narrowed in patient K.L. during both phases of the cardiac cycle. In addition, the aortic valve is normal in K.L. and no post-stenotic dilatation of the aorta is present. In patient K.L. the ventricle fails to empty completely in systole and muscle can be seen bulging into the ventricular cavity. These features are absent in the patients with aortic valve stenosis. 
cardiomyopathy from valvar and discrete subvalvar aortic stenosis. It should be emphasized that the appearance of the plain chest film is not distinctive, and in at least one case the appearances suggested that mitral stenosis was present. In contrast the angiographic appearances are unique to this disorder. The extraordinary, irregular outlines of the ventricular cavities, combined with the appearances of outflow tract obstruction, make the diagnosis secure.

The primary ætiology of this disorder remains unknown. The family incidence of at least 20 per cent in this series is in agreement with the reported experience of others. In 7 patients in this series a heart murmur had been known to be present before the age of 5 years, and in one had been heard at the age of 6 weeks. These findings strongly suggest a genetic basis for the disorder. Furthermore, it is becoming increasingly clear that this is a generalized disorder of cardiac musle and that the ventricular septum is not necessarily uniquely or primarily involved as previously thought. There appears to be a predisposition for the septum to enlarge disproportionately, since it is particularly massive in many cases (Menges et al., 1961; Paré et al., 1961; Teare, 1958).

Failure of the left ventricular outflow tract to open during ventricular ejection has been demonstrated by cine-angiography. In normal persons or in patients with aortic valve stenosis, the left ventricular outflow tract is open early in systole when the rest of the ventricle is ejecting, contracts late in systole to complete ejection, and finally relaxes in diastole. In patients with obstructive cardiomyopathy the outflow tract never opens completely and its relative narrowing during systole produces obstruction to ventricular ejection (Fig. 14). This finding is of great interest, for surrounding the outflow tract of the left ventricle is the deep bulbospiral muscle. In 1942 Robb and Robb had suggested on anatomical grounds that if this powerful sphincter contracted early it would produce narrowing of the aortic outlet and that this would be equivalent to aortic stenosis. It is still not certain whether functional narrowing of the left ventricular outflow results from massive and generalized hypertrophy or whether it is of primary importance in the ætiology of the disorder, the functional obstruction eventually leading to secondary generalized hypertrophy. In a number of cases although there is little or no hæmodynamic or angiographic evidence of outflow obstruction, massive hypertrophy can be seen angiographically, and in the majority of these patients a raised end-diastolic pressure has been recorded. Generally the pattern of hypertrophy, as seen angiographically, is very irregular: the large masses of muscle, which protrude into the ventricular cavities, cause them to lose the smooth appearance of concentric hypertrophy seen in valvar or discrete subvalvar obstruction. Although these two observations suggest that the generalized hypertrophy is not simply the result of functional outflow obstruction, the available evidence is insufficiently conclusive to permit us to say whether a disorder of function precedes hypertrophy or vice versa.

One may rightly inquire whether the patients presented in this report are a truly homogeneous group, or whether they represent a variety of disorders with some features in common. We believe that the group described here is in fact homogeneous. The clinical findings, taken together, present a distinctive pattern, and a majority of the significant clinical features described have been present in most of the patients. Furthermore, the angiocardiographic findings are, in our experience, unique to this disorder. The bizarre contours of the ventricular cavities due to bulging masses of irregularly hypertrophic muscle have not been seen in cardiomyopathy of the congestive or constrictive types. (Goodwin et al., 1961) of either known or unknown ætiology. The appearances are easily distinguished from those of concentric hypertrophy secondary to such lesions as discrete aortic valve stenosis. To our knowledge a similar appearance has not been reported for any primary disorder of heart muscle in which the ætiology is known. Taking these observations with the findings. suggesting that the disorder is based on a genetic fault, it seems reasonable to consider these patients. as a homogeneous group and, for simplicity, to consider that there is probably a single primary basis for the disorder. It is probably also true that at least some of the patients earlier described as. cases of "familial cardiomegaly" (Evans, 1949; Whitfield, 1961) suffered from obstructive cardiomyopathy, although the lack of hæmodynamic data in these earlier reports makes it difficult to. consider this more than a possibility. 


\section{SUMMARY}

Previous experience of obstructive cardiomyopathy has been reviewed and amplified in the light of further hæmodynamic and angiographic investigations in 29 patients. Since obstruction is variable and hypertrophy constant, the term "hypertrophic" has been added to the definition. Hypertrophic obstructive cardiomyopathy is a generalized disorder of heart muscle in which massive hypertrophy of the ventricular septum and of the free walls of the ventricles frequently results in outflow tract obstruction. This obstruction to outflow is partly mechanical and partly due to abnormal behaviour of the outflow pathways. Impaired function of ventricular muscle leads to restriction of inflow, and mitral regurgitation occurs in almost half the patients. There is a significant familial incidence suggesting a possible genetic basis.

Patients may present with symptoms and signs of either outflow obstruction or restriction of effective diastolic filling.

The disorder may be progressive, thus its treatment has been briefly discussed.

We are grateful to the Department of Medical Illustration and to Mrs. P. Smy for the illustrations and for the photographic reproductions. Our thanks are also due to Mr. Gerald Rainbow and his staff for technical assistance.

\section{REFERENCES}

Benchimol, A., Legler, J. F., and Dimond, E. G. (1963). The carotid tracing and apexcardiogram in subaortic stenosis and idiopathic myocardial hypertrophy. Amer. J. Cardiol., 11, 427.

Bercu, B. A., Diettert, G. A., Danforth, W. H., Pund, E. E., Jr., Ahlvin, R. C., and Belliveau, R. R. (1958). Pseudoaortic stenosis produced by ventricular hypertrophy. Amer. J. Med., 25, 814.

Bevegård, S., Jonsson, B., and Karlöf, I. (1962). Low subvalvular aortic and pulmonic stenosis caused by asymmetrical hypertrophy and derangement of muscle bundles of the ventricular wall. Acta med.scand., 172, 269.

Björk, V. O., Hultquist, G., and Lodin, H. (1961). Subaortic stenosis produced by an abnormally placed anterior mitral leaflet. J. thorac. cardiovasc. Surg., 41, 659.

Black. J. W. and Stephenson J. S. (1962). Pharmacology of a new adrenergic beta-receptor blocking compound (Nethalide). Lancet, 2, 311.

Boiteau, G. M., and Allenstein, B. J. (1961). Hypertrophic subaortic stenosis. Clinical and hemodynamic studies with special reference to pulse contour measurement. Amer. J. Cardiol., 8, 614.

Bourassa, M. G., Boiteau, G. M., and Allenstein, B. J. (1962). Hemodynamic studies during intermittent left bundle branch block. Amer. J. Cardiol., 10, 792.

Brachfeld, N., and Gorlin, R. (1959). Subaortic stenosis: A revised concept of the disease. Medicine (Baltimore), 38, 415.

- and - (1961). Functional subaortic stenosis. Ann. intern. Med., 54, 1.

Braunwald, E., and Ebert, P. A. (1962). Hemodynamic alterations in idiopathic hypertrophic subaortic stenosis induced by sympathomimetic drugs. Amer. J. Cardiol., 10, 489.

-, Morrow, A. G., Cornell, W. P., Aygen, M. M., and Hilbish, T. F. (1960). Idiopathic hypertrophic subaortic stenosis; clinical, hemodynamic and angiographic manifestations. Amer. J. Med., 29, 924.

Brent, L. B., Aburano, A., Fisher, D. L., Moran, T. J., Myers, J. D., and Taylor, W. J. (1960). Familial muscular subaortic stenosis. An unrecognised form of "idiopathic heart disease", with clinical and autopsy observations. Circulation, 21, 167.

Brock, R. (1957). Functional obstruction of the left ventricle (acquired aortic subvalvar stenosis). Guy's Hosp. Rep., 106, 221.

- (1959). Functional obstruction of the left ventricle (acquired aortic subvalvar stenosis). Guy's Hosp. Rep., $108,126$.

Evans, W. (1949). Familial cardiomegaly. Brit. Heart J., 11, 68.

Goodwin, J. F., Gordon, H., Hollman, A., and Bishop, M. B. (1961). Clinical aspects of cardiomyopathy. Brit. med. J., 1, 69.

- Hollman, A., Cleland, W. P., and Teare, D. (1960). Obstructive cardiomyopathy simulating aortic stenosis. Brit. Heart J., 22, 403 and 414.

-, Steiner, R. E., Hollman, A., and Oakley, C. M. (1962). Ventricular structure and function in obstructive cardiomyopathy. Proc. IVth World Congress of Cardiology. In the press.

Hancock, E. W. (1959). The diagnosis of subvalvar aortic stenosis. Brit. Heart J., 21, 581.

Hollister, R. M., and Goodwin, J. F. (1963). The electrocardiogram in cardiomyopathy. Brit. Heart J., 25, 357.

Hollman, A., Goodwin, J. F., Teare, D., and Renwick, J. W. (1960). A family with obstructive cardiomyopathy (asymmetrical hypertrophy). Brit. Heart J., 22, 449.

Menges, H., Jr., Brandenburg, R. O., and Brown, A. L. (1961). The clinical, hemodynamic and pathologic diagnosis of muscular subvalvular aortic stenosis. Circulation, 24, 1126.

- Moberg, A., Fix, P., and Söderberg, H. (1962). On the pathogenesis of idiopathic subaortic stenosis. Presented at XI Meeting of the European Society of Cardiovascular Surgery, July, 1962, Stockholm, Sweden. To be published in Acta radiol. (Stockh.). Summary in J. cardiovasc. Surg., 4, 602. (1963).

Morrow, A. G., and Braunwald, E. (1959). Functional aortic stenosis: A malformation characterized by resistance to left ventricular outflow without anatomic obstruction. Circulation, 20, 181. 
Nordenström, B., and Ovenfors, C. O. (1962). Low subvalvular aortic and pulmonic stenosis with hypertrophy and abnormal arrangement of the muscle bundles of the myocardium. Acta radiol. (Stockh.), 57, 321.

Paré, J. A. P., Fraser, R. G., Pirozynski, W. J., Shanks, J. A., and Stubington, D. (1961). Hereditary cardiovascular dysplasia. A form of familial cardiomyopathy. Amer. J. Med., 31, 37.

Robb, J. S., and Robb, R. C. (1942). The normal heart. Anatomy and physiology of the structural units. Amer. Heart J., 23, 455.

Shabetai, R., and McGuire, J. (1963). Idiopathic cardiac hypertrophy simulating valvular heart disease. Amer. Heart J., 65, 124.

Soulié, P., Joly, F., and Carlotti, J. (1962). Les sténoses idiopathiques de la chambre de chasse du ventricule gauche. Acta cardiol. (Brux.), 17, 335.

Steiner, R. E., and Hollman, A. (1962). Radiological contrast studies of the left heart. Brit. J. Radiol., $35,540$.

Teare, D. (1958). Asymmetrical hypertrophy of the heart in young adults. Brit. Heart J., $20,1$.

Whalen, R. E., Cohen, A. I., Sumner, R. G., and McIntosh, H. D. (1963). Demonstration of the dynamic nature of idiopathic hypertrophic subaortic stenosis. Amer. J. Cardiol., 11, 8.

Whitfield, A. G. W. (1961). Familial cardiomyopathy. Quart.J. Med., 30, 119.

Wigle, E. D. (1963). The arterial pressure pulse in muscular subaortic stenosis. Brit. Heart J., $25,97$.

, Chrysohou, A., and Bigelow, W. G. (1963). Results of ventriculomyotomy in muscular subaortic stenosis Amer. J. Cardiol., 11, 572.

- Heimbecker, R. O., and Gunton, R. W. (1962). Idiopathic ventricular septal hypertrophy causing muscular subaortic stenosis. Circulation, 26, 325. 